\title{
Complementing mathematics support with online MathsCasts
}

\author{
B. Loch $^{1} \quad$ O. Gill $2 \quad$ A. C. Croft $^{3}$
}

(Received 16 December 2011; revised 16 December 2012)

\begin{abstract}
Widening of participation and budget cuts are strong drivers to motivate the investigation of educational technologies to benefit students seeking help in mathematics support centres. In Australia, the uncapping of university places by the Government from 2012 (with one explicit aim to increase the number of students from non-traditional backgrounds) may lead to an influx of students that are mathematically less prepared. At the same time European universities face financial challenges as a result of the Global Financial Crisis. This paper reports on an international research collaboration between mathematics support centres in Australia, Ireland and the UK. At all three universities, existing pedagogical expertise and knowledge of the topics and concepts students struggle with informed the production of MathsCasts - short screen movement videos of mathematical explanations recorded by a tutor using tablet technology. MathsCasts provide students with the
\end{abstract}

http://journal .austms.org.au/ojs/index.php/ANZIAMJ/article/view/4984 gives this article, (c) Austral. Mathematical Soc. 2012. Published December 19, 2012. ISSN 1446-8735. (Print two pages per sheet of paper.) Copies of this article must not be made otherwise available on the internet; instead link directly to this URL for this article. 
flexibility to receive mathematical explanations whenever they like and from wherever they are. We overview the collaboration undertaken to get this project to its first roll-out phase. We then state and address specific questions relating to student use of MathsCasts and perceived benefits to students, and discuss lessons learnt from the feedback which will inform whether and how future MathsCasts will be made. We present findings of an early evaluation of the impact of MathsCasts on student learning across the three universities and outline plans for the future. The paper will benefit those who teach and support students who struggle with mathematics at university and those who wish to exploit emerging technologies to further their own teaching.

\section{Contents}

1 Introduction and background

2 What are MathsCasts?

C564

3 The production of MathsCasts

C565

4 Preliminary evaluation

C567

5 Discussion, conclusions and ongoing work

C570

References

C573

\section{Introduction and background}

Over the last twenty years or so, problems associated with teaching mathematics to university students, particularly those for whom mathematics is not their specialisation, have emerged in various parts of the world. In the UK, high-level reports and research papers have highlighted students' lack 
of basic skills and lack of preparedness for the demands of higher education which leads to high failure rates in some courses [13,12]. Similar problems are reported in Ireland [11] and Australia [8].

In response to these problems, universities began to investigate modes of better supporting students' transition to, and participation in, undergraduate courses. Mathematics support centres are one such mode: dedicated, physical spaces in which learning activities are offered in addition to traditional forms of teaching. Student participation is voluntary, and tutors are available at specified times for one-to-one support.

The reasons for the continued development of support centres are many. The overall result is that the user uptake continues to increase. For example, in 2009 the participation rates at the Limerick centre were more than double those in the year of its founding, eight years previously [4]. As the number of users of mathematics support is on the increase, the onus is on centre managers to not only respond to their needs but also look into ways in which support can be offered efficiently and effectively. Front-end tutorials, drop-in centres, diagnostic testing, study facilities, examination revision programmes, bridging courses, help sheets and online support are some of the facilities provided with one-to-one tuition being most favoured by students [4].

Technological advance is now rapid. It is possible to provide additional support in different ways, with relative ease and relatively modest investment. This paper reports on a collaborative research project between the learning support centres at the University of Limerick, Loughborough University and Swinburne University of Technology which aims to investigate the potential of using technology to provide more flexible mathematics support. The objective is to add to mechanisms already in place, by providing e-learning resources available around the clock and accessible from anywhere. The two main motivators for undertaking this project are:

- To find a sustainable solution to long-term provision of 'anytime' support in this delicate economic climate, where support centre opening times and tutor allocations may be reduced, and where students are working 
part time and may be unable to visit during opening hours;

- To appeal to a new cohort of students who have grown up with the Web as a major source of information, and who may have a preference for multimedia resources rather than for paper-based material.

The collaborative research project investigates:

- how MathsCasts should be designed to be most effective;

- what topics are appropriate for online study; and

- how to encourage students to watch the recordings.

Specifically, this paper describes how the collaboration was approached.

\section{What are MathsCasts?}

MathsCasts are screencasts - narrated recordings of handwritten communication on a computer screen. It is this visual representation that separates them from traditional podcasts which are mostly aural [5]. They can be accessed via mobile phones, portable video players or computers and allow communication through multiple channels: writing, visual aids and speech [9]. In the context of mathematics teaching and learning, screencasts enable the real-time recording of handwritten step-by-step solutions of problems including specialist mathematical notation [9]. Mathematical screencasts help students see at what point they have gone off-track in their solution [6].

Many of today's students own a portable video player or a multimedia-capable mobile phone, and educators may take advantage of this by creating resources that students can access at any time in any place.

We emphasise that while MathsCasts are video resources to explain concepts that were not understood in class, they lack the interactivity, dialogue and availability of immediate feedback that a face-to-face visit to a maths support 
centre would provide. MathsCasts deliver more flexible learning options to students but do not replace the support given by a tutor. Indeed, "mobile learning ... offers educators a means to design learning activities and resources that allow students to individualise their learning" [14]. However, there has been some criticism of mathematical screencasts in that they do not challenge students by bringing up and discussing common misconceptions. Muller [10] suggested that "perhaps videos are just too passive a medium to attract attention for ten minutes". Notwithstanding these reservations we believe that MathsCasts have a role to play in mathematics support and it is this role which is the focus of our research.

\section{The production of MathsCasts}

MathsCasts are produced by tutors and lecturers at the three collaborating universities, with internal funding provided at two of these to pay tutors for the preparation of the recordings. While we are aware that a large number of screencasts are available on the web already ${ }^{1}$ it was felt that our students would benefit more from MathsCasts tailored specifically to their needs. MathsCasts are more closely aligned with the support students receive in their own drop-in centres in terms of content, notation, style and specific examples from their mathematics modules. Therefore, each university selects topics to match local needs, based on the mathematics support and teaching experiences of those involved. All recordings are produced following common specification guidelines. These include a common look front and end slides, tailored for each institution (see Figure 1). A Creative Commons licence $(\mathrm{BY}, \mathrm{ND}, \mathrm{NC})^{2}$ has been applied to MathsCasts, which means that they are available for free to anyone to use for non-commercial purposes (NC), as long as they remain unchanged (ND) and authorship is acknowledged (BY).

\footnotetext{
${ }^{1}$ http://www.khanacademy . org/ e.g.

${ }^{2}$ http://creativecommons.org/
} 


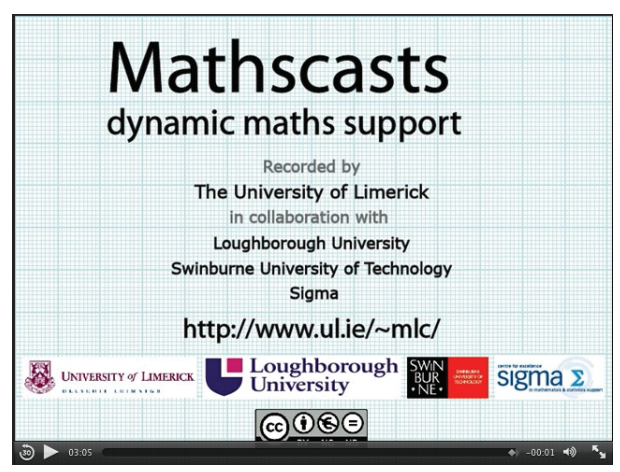

Figure 1: End Slide of a University of Limerick MathsCast.

Swinburne University is hosting the MathsCasts via iTunes U and YouTube. Navigational aids are currently being added to the project website ${ }^{3}$ which will soon be the main portal for anyone to search for recordings.

Each screencast undergoes a review process for quality control purposes before it is released as a MathsCast. A rubric for creating and reviewing MathsCasts was designed for current and future recorders and reviewers and to create consistency between the recordings in the three universities. Issues addressed in the production rubric include preparation of text, assumption of knowledge, clarity of speech and writing, technical considerations such as using the mouse pointer to illustrate a point and finishing considerations such as length and polishing or editing of MathsCasts. Importantly, emphasis was placed on teaching methods which promote understanding as well as procedural skills, a move intended to address a lack of conceptual understanding of mathematics fundamentals on entry and poor study habits sometimes acquired at school level [1]. Figure 2 shows a screenshot from a MathsCast on differential equations.

For critiquing MathsCasts, reviewers are given a checklist which covers clarity, pace, length, look and feel of a MathsCast, assumption of knowledge, use of

${ }^{3}$ http://mathscasts.org 


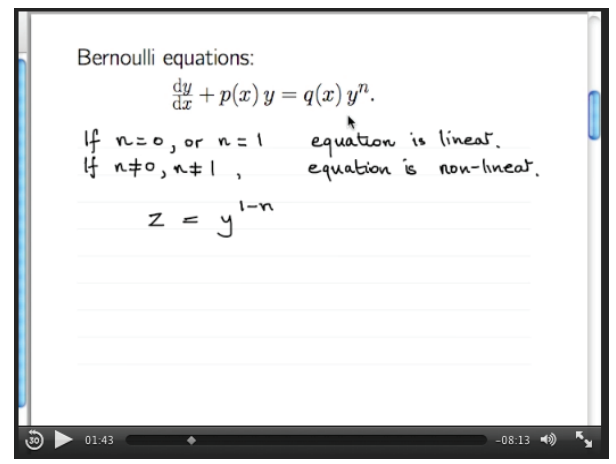

Figure 2: A screenshot of a MathsCast on solving differential equations.

available tools and suggestions for improvement.

At the end of 2012, there will be around 250 MathsCasts online, with around 150 waiting for review or for publication.

\section{Preliminary evaluation}

At this relatively early stage of the collaboration we are interested in the following specific research questions:

- Will students make use of MathsCasts to support their learning?

- What factors encourage students to use MathsCasts to support their learning?

- What are the perceived benefits of accessing MathsCasts?

- What lessons can we learn from the feedback, in particular regarding whether and how future MathsCasts should be made?

In order to answer these research questions a group of students was identified in each institution, and these students were given access to only those MathsCasts 
relevant to their current unit of study. The feedback acquired from students at each university is now outlined.

Loughborough University The MathsCasts were used to support a group of first and second year undergraduates majoring in mathematics who were studying a first unit in Differential Equations. In the end of semester teaching quality survey which was completed by 139 of the 220 enrolled students, twelve specifically mentioned MathsCasts in the two free-text comment boxes with questions: What did you like about this module? and How could the module be improved? These unexpected responses were entirely positive. Students liked that "the videos of the solutions [to tutorial questions] were very useful", and that "the course materials including screencasts were all very good/clearly thought out". To improve the unit, they suggested to "do more video solutions", and "more video for different examples".

An unsolicited email came from a student on the course, who has an autism spectrum disorder and "often find[s] lecture halls and tutorial rooms confusing and distracting". He finds it difficult to concentrate in these environments and perceives student/tutor interaction as stressful. The MathsCasts transformed the module for him, as he can now play the video in a quiet environment, with pausing and fast-forwarding available as needed. He said that "It is like having a teacher on demand".

This student went on to pass the module at a high level and after the examination wrote:

Just to let you know, the screencasts were very useful before the final exam. I watched them the day before and achieved my best exam result of semester two. I'm sure this was because the concepts were crisp and clear after viewing the explanations once more. If something similar was available for other modules I think my grades would be higher. 
University of Limerick The Mathematics Learning Centre runs a one week mathematics revision programme (Head Start Maths) for adult learners about to embark on a mathematics intensive degree programme. Many of these students have been out of formal education for up to 20 years and have no formal school leaving qualification [2]. Students attend lectures and workshops and have access to a set of workbooks [3] to accompany the lectures and workshops. In 2011, a suite of MathsCasts was created to supplement the programme.

At the end of the programme, 16 out of the 36 enrolled students stated that they had used the MathsCasts on a daily basis throughout the course. The feedback was unanimously positive. For instance, all 16 students responded "yes" to the question "Did you find the screencasts useful?" Positive aspects noted included the ability to replay the recordings, to revisit from home, to pause when needed, and also to "consolidate some things ... learned earlier in the week". One of the students commented that the MathsCasts are a "good way to prepare for the lecture", and another thought they "break down [the] reasoning behind maths". All respondents were satisfied with the pace of the screencasts, and 15 students rated the clarity of explanations as good to excellent. Most importantly, students could see value in MathsCasts as "they explain what the reason for using a particular formula or rule is". All but one student believed that conceptual understanding could be enhanced by watching MathsCasts and gave reasons such as learning at your own pace, clear explanation of concepts, reinforcement of what was covered in class, and also "different stimulation". Suggestions for improvements were to provide more MathsCasts. Fifteen students stated that they would continue to access MathsCasts when they formally started their degree studies. The feedback indicates the teaching for understanding methodology that is encouraged within each recording is recognised and valued by the students.

Swinburne University of Technology The MathsCasts were promoted as part of the service offered by the Maths and Stats Help (MASH) Centre to all new first year students during orientation sessions at the start of the 
academic year in February 2011. A survey across four first year mathematics units for Engineering, Science and Aviation students (144 responses) at the end of the semester revealed that only ten students had watched the screencasts. These students were very positive. When asked what value they saw in watching the MathsCasts, comments were "the ability to pause and review steps and an actual guide is really useful. They are vital to my style of learning." and "I can see step-by-step solutions". Those who said they had not watched any commented "Wasn't aware of them" or "I know that they are there but I never seem to get round to them". These two types of responses led to the questions of how to encourage students to watch MathsCasts, and how to make MathsCasts more engaging so that students will find the time and motivation to watch them [7]. In the following semester, MathsCasts were linked-to from within the BlackBoard Learning Management System (LMS, also known as VLE) and actively promoted by the lecturers of all four parallel streams in a first year second semester mathematics unit for engineers. Feedback received in the first few weeks of semester via a short online survey (13 students) showed that more than two thirds of students watch a complete MathsCast from start to end. More than 50\% responded that they watched some MathsCasts more than once. Suggestions on how to improve the MathsCasts included to "have a little review of the section that ur [sic] explaining the example to". The students asked for "all of the chapters" to be covered, and "have once a week one question explained in detail from a past exam". Further comments included "I think other than lectures and tutorials, Mathscasts are the most powerful tools. Simply the best."

\section{Discussion, conclusions and ongoing work}

This preliminary evaluation enables us to offer answers to the research questions stated earlier. 
Will students make use of MathsCasts to support their learning? There are clearly students who value the MathsCasts sufficiently highly to make use of them to support their learning. For example, the 16 of 36 students at the University of Limerick who used them on a daily basis showed this to be the case. The twelve Loughborough University students who offered unsolicited free-text responses about their use of MathsCasts endorse this fact. Furthermore, our findings lead us to believe that decisions we have made regarding topics, level of difficulty of the material, pace, and design are largely along the right lines.

What factors encourage students to use MathsCasts? When MathsCasts were promoted through the MASH Centre at Swinburne, the uptake was somewhat less than first expected. The feedback received, particularly in the first pilot semester at Swinburne, highlighted a lack of engagement by students with MathsCasts. On the other hand, when MathsCasts were linked explicitly to specific courses the picture is quite different as we saw from the Loughborough and Limerick data, and the later data from Swinburne. So, considerable thought needs to be given to how the MathsCasts are presented to the students - it would seem the ideal way is to link via the resources of their specific mathematics modules. However, from the point of view of a central mathematics support provider, this is difficult. It requires each individual module lecturer to know about and make the required links.

What are the perceived benefits? Students at all three universities gave similar reasons why they thought MathsCasts were beneficial to them. Preparation, consolidation, revision, explanations, improved understanding and reasoning are all given as reasons why students choose to use MathsCasts. Our findings suggest that MathsCasts may be particularly beneficial to students with special or additional needs, and those who cannot engage with a course in a traditional way due to particular personal circumstances. 
What lessons can we learn? A careful analysis of student feedback is necessary in order to inform improved instructional design of mathematical screencasts. For example, students responded that they would like to see more use of colour. In addition, tools, such as GeoGebra for constructing graphs, may be able to make the MathsCasts more appealing. Challenging misconceptions through MathsCasts [10] is worth consideration, although to some extent this already happens in some MathsCasts where the presenter points out where students usually go wrong. It will be worth investigating whether students who would not usually ask for help in the mathematics support centre, perhaps through lack of confidence, would indeed be willing to watch MathsCasts, and if so, whether this leads to improved performance. Some students may no longer or less frequently visit the mathematics support centre as their questions are answered within MathsCasts. Others may visit more often as their interest in mathematics, or confidence to ask questions, may have increased. Finally, it was noticed over the course of the project that there are differences in students' mathematics backgrounds and topics studied between institutions. For example, a whole stream of MathsCasts was created at Swinburne to cover the topics engineering students in their second semester of first year usually struggle with. The Swinburne students responded that the level of difficulty and detail was appropriate for their needs. However, few of these MathsCasts were deemed appropriate for students at the University of Limerick. This raises a more general question: Are MathsCasts transferrable? Can, and should, mathematical screencasts be shared between universities, or is there a rational basis to the anecdotal evidence we have observed that many mathematicians do not endorse explanations produced by others? Should every university create their own collection of MathsCasts? Another lesson learnt is that much more active promotion is required than was expected. More research is needed on how to engage students actively with MathsCasts, perhaps through better promotion and improved navigation. But it would seem that students' primary routes to the MathsCasts should be through links from the specific module pages on the LMS. These and related issues will continue to attract the attention of the research team in the months ahead. 
The authors invite readers of this paper to visit the site, ${ }^{4}$ view some of the MathsCasts and to complete the online survey.

Acknowledgements The authors acknowledge assistance from the Library team at Swinburne University of Technology who provided designs, technical support and advice and established the MathsCasts iTunes U presence to which content is regularly uploaded. We also thank the tutors who produced the MathsCasts, and the students who provided feedback.

\section{References}

[1] Gill, O. What Counts as Service Mathematics? An Investigation into the Mathematics Problem in Ireland. PhD: University of Limerick. C566

[2] Gill, O. Evaluating the Impact of a Refresher Course in Mathematics on Adult Learners. In Christensen, H. et al (Eds), Proceedings of the 17th International Conference of Adults Learning Mathematics (ALM), 2010, pages $37-46$. C569

[3] Gill, O. Head Start Mathematics - Report on a Programmme for Adult Learners of Mathematics Returning to Higher Education. In Green, D. (Ed) Proceedings of CETL-MSOR Conference 2008 (Continuing Excellence in the Teaching \& Learning of Maths, Stats \& OR), Lancaster University, Lancaster, 2008, pp. 33-37. http: //mathstore.ac.uk/repository/CETLMSOR2008_Proceedings.pdf C569

[4] Gill, O., O'Donoghue, J., Faulkner, F. and Hannigan, A. Trends in Performance of Science and Technology Students (1997-2008) in Ireland, International Journal of Mathematical Education in Science and

${ }^{4}$ http://mathscasts.org 
Technology 41(3), 2010, 323-339. DOI:10.1080/00207390903477426 C563

[5] Jordan, C., Loch, B., Lowe, T., Mestel, B. and Wilkins, C. Do short screencasts improve student learning of mathematics? MSOR Connections 11(4), 2012.

http://mathstore.ac.uk/headocs/Connections_12_1_Jordan.pdf C564

[6] Loch, B. Screencasting for mathematics online learning a case study of a first year Operations Research course at a dual-mode Australian university. Chapter in: Teaching Mathematics Online: Emergent Technologies and Methodologies. A. A. Juan, M. A. Huertas, S. Trenholm \& C. Steegman. Advances in Distance Education Technologies (ADET) Book Series. IGI Global, 2012, 43-59. C564

[7] Loch, B. and McLoughlin, C. An instructional design model for screencasting: Engaging students in self-regulated learning. In G. Williams, P. Statham, N. Brown \& B. Cleland (Eds.), Changing Demands, Changing Directions. Proceedings ascilite Hobart, 2011, 816-821. http://www.leishman-associates.com.au/ascilite2011/ downloads/papers/Loch-concise.pdf C570

[8] MacGillivray, H. Learning Support in Mathematics and Statistics in Australian Universities: A Guide for the University Sector. Australian Learning and Teaching Council, Sydney, 2008. C563

[9] Mullamphy, D. F., Higgins, P. J., Belward, S. R., and Ward, L. M. To screencast or not to screencast. ANZIAM J. 51 (EMAC2009), 2010, C446-C460. http://journal. austms.org.au/ojs/index.php/ ANZIAMJ/article/view/2657 C564

[10] Muller, D. Khan Academy and the Effectiveness of Science Videos. 17 March 2011. http://www.veritasium.com/2011/03/ khan-academy-and-effectiveness-of .html C565, C572 
[11] O'Donoghue, J. (1999) An intervention to assist at risk students in service mathematics courses at the University of Limerick: University of Limerick teaching fellowship scheme, University of Limerick, Limerick. C563

[12] Smith, A. Making mathematics count. The report of Professor Adrian Smith's inquiry into post-14 mathematics education. 2004. Report for DfES (London). C563

[13] Sutherland, R. and Dewhurst, H. Mathematics Education: Framework for progression from 16-19 to HE. University of Bristol, Graduate School of Education. 1999. ISBN 0862924871 C563

[14] Sutton-Brady, C., Scott, K.M., Taylor, L., Carabetta, G., and Clark, S. The value of using short-format podcasts to enhance learning and teaching. ALT-J, Research in Learning Technology, 17 (3), 2009, 219-232. C565

\section{Author addresses}

1. B. Loch, Mathematics, FEIS, Swinburne University of Technology, H38, PO Box 218, Hawthorn, Victoria, 3122 Australia. mailto:Birgit.Loch@swin.edu.au

2. O. Gill, National Centre for Excellence in Mathematics and Science Teaching and Learning, University of Limerick, Ireland mailto:Olivia.Fitzmaurice@ul.ie

3. A. C. Croft, Mathematics Education Centre, Loughborough University, Loughborough, UK. LE11 3TU. mailto:A.C.Croft@lboro.ac.uk 